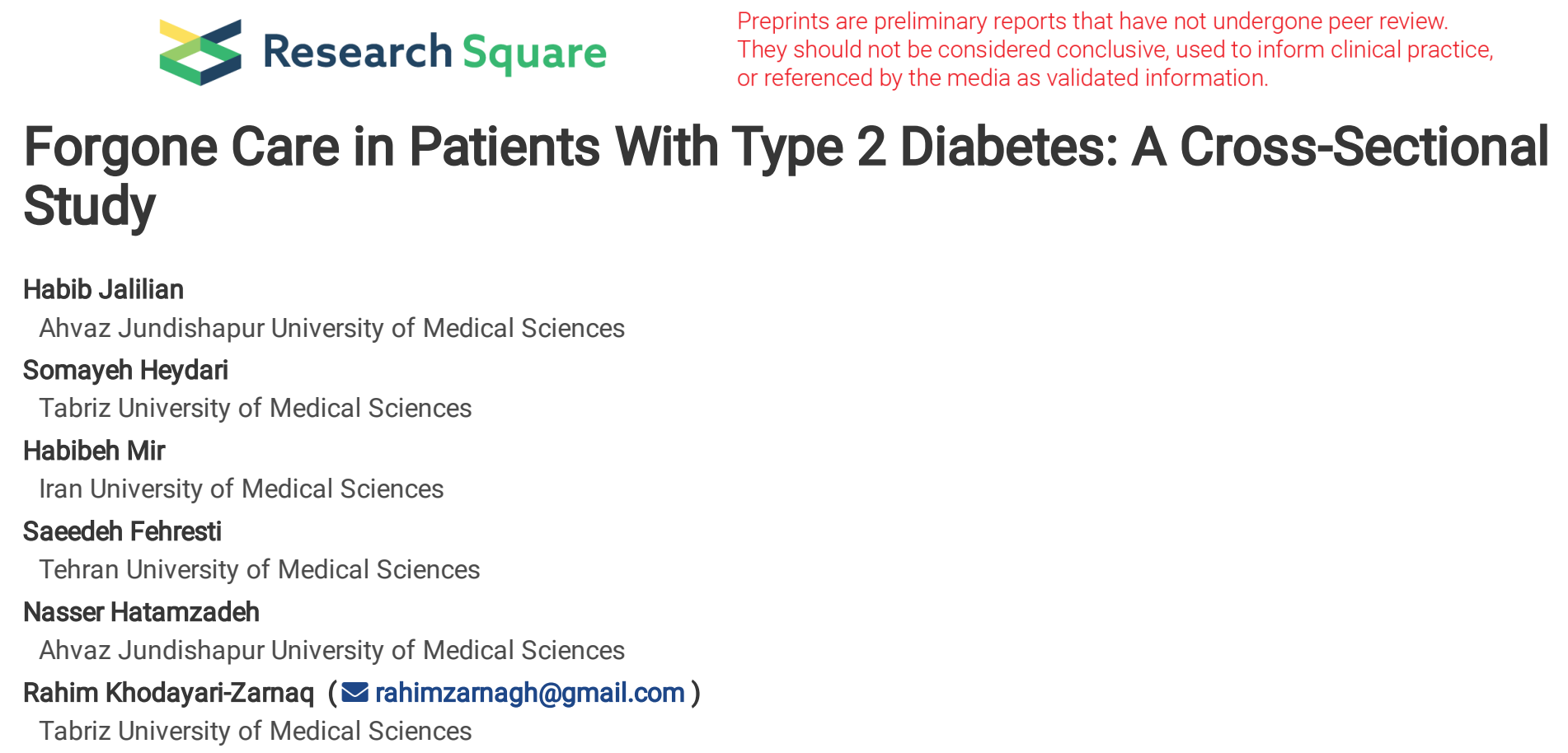

\section{Forgone Care in Patients With Type 2 Diabetes: A Cross-Sectional Study}

Habib Jalilian

Ahvaz Jundishapur University of Medical Sciences

Somayeh Heydari

Tabriz University of Medical Sciences

Habibeh Mir

Iran University of Medical Sciences

Saeedeh Fehresti

Tehran University of Medical Sciences

Nasser Hatamzadeh

Ahvaz Jundishapur University of Medical Sciences

Rahim Khodayari-Zarnaq ( $\square$ rahimzarnagh@gmail.com )

Tabriz University of Medical Sciences

Research Article

Keywords: type 2 diabetes, forgone care, treatment withdrawal, treatment discontinuation, relinquished care, delayed care

Posted Date: March 1st, 2021

DOl: https://doi.org/10.21203/rs.3.rs-238281/v1

License: (1) This work is licensed under a Creative Commons Attribution 4.0 International License. Read Full License 


\section{Abstract}

Background and objective: Diabetes mellitus is a complex chronic disease requiring appropriate continuous medical care and delayed, or forgone care may exacerbate the severity of the disease. This study aimed to investigate the factors affecting forgone care in diabetic patients.

Materials and methods: This was a cross-sectional study involving 1139 patients with type 2 diabetes aged 18 years and older in East Azerbaijan. Data collected using a researcher-made questionnaire and analyzed using SPSS software version 22.

Results: Of the 1139 patients, 510 patients (45\%) reported forgone care during the last year. The percentage of forgoing care was higher in patients without supplementary insurance coverage $(P=0.01)$, those with complications $(P=0.01)$ and those with the history of hospitalization $(P=0.006)$. The majority of patients $(41.5 \%)$ reported that the most important reason for forgoing care is financial barriers resulting from disease treatment costs. Of the main four factors, quality of care had the highest impact on forgone care at $61.28 \pm 39.74$, followed by accessibility $(37.01 \pm 25.12)$, awareness and attitude towards disease $(18.52 \pm 18.87)$ and social support $(17.22 \pm 18.80)$.

Conclusion: The results showed that, despite the implementation of the Islamic Republic of Iran on a fast-track to beating noncommunicable diseases (IraPEN), a considerable number of diabetics had a history of forgoing care, and the most important reasons for forgoing care were related to the financial pressure and dissatisfaction with the quality of care. Therefore, not only more financial support programs should be carried out, but the quality of care should be improved.

\section{Introduction}

Type 2 Diabetes Mellitus is a complex chronic disease requiring appropriate continuous medical care (1). Type 2 diabetes patients are often prescribed multiple medications to treat hyperglycemia, diabetes-related conditions like hypertension and dyslipidemia, and other comorbidities and complications. For those with diabetes, adherence to medications is associated with better control of intermediate risk factors (2-5), lower odds of hospitalization (4, 6-8), lower health care costs $(6,8-10)$, and lower mortality $(4,6)$. On the other hand, access to equitable healthcare, pursuant to need, and regardless of demographic, ability to pay or social background, is an important goal for global healthcare systems (11). Therefore, unmet need in health care systems is found as an undesirable feature (12).

Foregone care is one aspect of healthcare access; a person with forgone care needs is defined as one who does not use healthcare, despite perceiving a need for it. Forgone care is an important aspect in health system performance assessment as it shows a gap between the perceived need for health care and utilization. Further, forgone care is a highly important indicator for inequalities in access to health care. The consequences of forgone care are manifold such as "feeling worried" and/or problems with daily activities, higher use of emergency departments, the progression of the disease or result in the need for more complex treatment, lead to an increase in the utilization rate of health services in the future and finally, increase the health care expenditures (13-19). The assessment of forgone care is mostly based on self-reports. Even though this is a subjective statement, it clearly shows a considerable discomfort with the health care system, and it could also show a lost chance for improving the health status (20). The decision not to seek health care when one feels that care is needed (forgone care) is influenced by different factors (13). Some of which may be amenable to policy intervention. (21). Therefore, the present study aimed to investigate the rate and causes of forgone care in patients with type 2 diabetes.

\section{Methods}

\section{Study design}

This cross-sectional study was conducted on patients with type 2 diabetes aged 18 years or older in the East Azerbaijan province.

\section{Data collection tools}

The researcher-made questionnaire was used to examine the factors affecting foregone care. The questionnaire consists of three parts; 1 demographic and socioeconomic variables, 2-variables related to disease (chronicity (in years) of DM, Type of current treatment, presence of co-morbidity or complications, the history of hospitalization due to complications of DM during the last year, disease severity) and 3 - items related to reasons of forgoing care in type 2 diabetes patients.

After reviewing the related literature, 15 interviews with type 2 diabetes patients and 8 interviews with doctors, nurses, and primary health care providers were conducted to develop the questionnaire. After reviewing the related literature and analyzing the interviews, 22 questions were extracted. In the next step, to assess the validity of the questionnaire, the questionnaire was given to 40 experts, including 
faculty members, specialist doctors, general practitioners, nurses and primary health care providers. Then, Content Validity Index (CVI) and content validity ratio (CVR) were computed using Excel software for each question. Four questions did not meet the acceptable scores and removed from the questionnaire. In order to assess the reliability of the questionnaire, internal consistency and Cronbach's alpha was used. Data were entered into the SPSS software version 22 for conducting Exploratory Factor Analysis after distributing the questionnaire among patients. The Principal Component Analysis method was used to extract the dimensions.

Furthermore, each question was rated on a 5-point Likert scale; (1-Very low importance, 2- Low importance, 3- moderately important, 4more important and 5- much more important) with higher scores indicating more impact forgone care. The degree of importance of each dimension was obtained through the total mean score for each dimension.

\section{Sample size and sampling methods}

According to the prevalence rate of diabetes (8.5\%) in East Azerbaijan province (22) and the population size of East Azerbaijan province ( 2016 census, $3,900,000$ people), the total number of people with diabetes estimated at 331,500 . So the estimated sample size using the Cochran's Sample Size Formula $(n=N t 2 p q / N d 2+t 2 p q)$ was 384 patients. However, considering the impact of sample size on results of factor analysis (a larger sample will lead to more reliable results) and the impossibility of conducting random sampling, with the research team's consensus, 1200 patients were selected through consecutive sampling methods. Comrey and Lee (1992) provided the following guidance in determining the adequacy of sample size: $100=$ poor, $200=$ fair, $300=$ good, $500=$ very good, 1,000 or more $=$ excellent (23).

\section{Data analysis}

Data analysis was performed using SPSS software version 22. Descriptive statistics (frequency and percentage, mean and standard deviation) were used to assess the most common reasons for forgoing care and the importance of each factor affecting associated with forgone care. In the analytical section, the Chi-Square (K2) test applied to examine the association between the socio-economic and disease-related variables on the status of forgoing treatment. Also, T-test and one-way ANOVA were used to investigate the association between the socio-economic and disease-related variables and the total score of reasons associated with forgone care. A binary logistic regression model was applied to estimate the odds ratios for reported forgone care.

\section{Results}

\section{Demographic and disease profile}

Descriptive statistics for the study sample are shown in Table 1. Approximately two-thirds of patients were women (66.3\%). Most patients $(52.5 \%)$ had an income of $<1500$ (international \$) and were illiterate or only able to read and write $(72.2 \%)$. Most people were treated with oral agents (54.3\%) and insulin (39.4\%), and only a small percentage of patients used behavior change. $72 \%$ responded they were aware

of their disease for more than five years. More than two-thirds of the patients $(76.1 \%)$ were afflicted with at least one of the complications of diabetes, and nearly one-third of patients (30.2\%) were hospitalized during the last year due to diabetes complications. $58.7 \%$ of the patients reported that their disease was severe.

\section{Table 1 Demographic and clinical profile and the frequency of forgone care}




\begin{tabular}{|c|c|c|c|c|c|}
\hline Variables & Categories & $\begin{array}{l}\text { Frequency } \\
\text { (Percent) }\end{array}$ & $\begin{array}{l}\text { The history of } \\
\text { forgone care \% }\end{array}$ & $x^{2}$ & $\begin{array}{l}P \text { - } \\
\text { value }\end{array}$ \\
\hline \multirow[t]{2}{*}{ Gender } & Male & $384(33.7)$ & 47.3 & \multirow[t]{2}{*}{1.17} & \multirow[t]{2}{*}{.27} \\
\hline & Female & $755(66.3)$ & 43.9 & & \\
\hline \multirow[t]{3}{*}{ Age } & $<40$ & $127(11.2)$ & 50.8 & \multirow[t]{3}{*}{3.19} & \multirow[t]{3}{*}{.20} \\
\hline & $40-60$ & $527(46.3)$ & 46.0 & & \\
\hline & $>60$ & $485(42.6)$ & 42.4 & & \\
\hline \multirow[t]{2}{*}{ Marital status } & Married & $933(81.9)$ & 43.7 & \multirow[t]{2}{*}{3.57} & \multirow[t]{2}{*}{.059} \\
\hline & Single & $206(18.1)$ & 51.0 & & \\
\hline \multirow[t]{2}{*}{ Income status } & $<1500$ international \$ & $397(52.5)$ & 44.9 & \multirow[t]{2}{*}{.36} & \multirow[t]{2}{*}{.54} \\
\hline & > 1500 international \$ & $359(47.5)$ & 42.7 & & \\
\hline \multirow[t]{4}{*}{ Education status } & Illiterate & $473(41.5)$ & 48.6 & \multirow[t]{4}{*}{6.81} & \multirow[t]{4}{*}{.07} \\
\hline & Reading and writing ability & $407(35.7)$ & 44.4 & & \\
\hline & Diploma & $195(17.1)$ & 37.6 & & \\
\hline & Academic education & $64(5.6)$ & 44.4 & & \\
\hline \multirow[t]{2}{*}{ Habitant status } & Urban & $1003(88.1)$ & 45.2 & \multirow[t]{2}{*}{.27} & \multirow[t]{2}{*}{.60} \\
\hline & Rural & $135(11.9)$ & 42.9 & & \\
\hline \multirow[t]{2}{*}{ Type of basic health insurance } & Iranian health insurance & 707 (64.4) & 47.7 & \multirow[t]{2}{*}{2.21} & \multirow[t]{2}{*}{.13} \\
\hline & Social security & $391(35.6)$ & 43.0 & & \\
\hline \multirow{2}{*}{$\begin{array}{l}\text { Supplementary health insurance } \\
\text { status }\end{array}$} & Yes & $430(39.1)$ & 40.4 & \multirow[t]{2}{*}{6.43} & \multirow[t]{2}{*}{.01} \\
\hline & No & $669(60.9)$ & 48.0 & & \\
\hline \multirow[t]{3}{*}{ Chronicity (in years) of DM } & $<5$ year & $421(37.1)$ & 48.0 & \multirow[t]{3}{*}{2.50} & \multirow[t]{3}{*}{.28} \\
\hline & 5 to 10 years & $260(22.9)$ & 42.5 & & \\
\hline & $>10$ years & $455(40.1)$ & 43.6 & & \\
\hline \multirow[t]{3}{*}{ Type of current treatment } & Oral pills & $619(54.3)$ & 45.8 & \multirow[t]{3}{*}{.87} & \multirow[t]{3}{*}{.64} \\
\hline & Insulin & $449(39.4)$ & 44.7 & & \\
\hline & $\begin{array}{l}\text { Change in lifestyle (change in diet } \\
\text { and physical activity) }\end{array}$ & $71(6.2)$ & 40.0 & & \\
\hline Presence of co-morbidity or & Yes & $867(76.1)$ & 47.2 & 6.64 & .01 \\
\hline & No & $272(23.9)$ & 38.2 & & \\
\hline Hospitalization due to complications & Yes & $344(30.2)$ & 51.2 & 7.50 & .006 \\
\hline & No & $795(69.8)$ & 42.4 & & \\
\hline Disease severity & Sever & $669(58.7)$ & 51.7 & 35.71 & $<$ \\
\hline & Moderate & $232(20.4)$ & 29.6 & & \\
\hline & Mild & $238(20.9)$ & 41.2 & & \\
\hline
\end{tabular}


Kaiser-Meyer-Olkin (KMO) Measure of Sampling Adequacy was .869, and Bartlett's Test of Sphericity was <.0001 (Appendix 1 Table 1). The results of exploratory factor analysis showed that the questions categorized into four dimensions (factors), including Quality of care (7 questions), Social support (4 questions), Awareness of and attitude towards disease and treatment (4 questions) and Accessibility (3 questions) (Appendix 1 Table 3). The validity of the questionnaire was evaluated using content validity. The mean scores for the CVI and CVR were 0.89 and 0.63 , respectively. The reliability of the questionnaire was evaluated via internal consistency, and Cronbach's alpha was 0.83 .

\section{The results of the rate of and the reasons for foregone care}

Of the 1133 patients, $510(45 \%)$ patients reported forgone care during the last year, which was higher in patients without supplementary insurance $(P=0.01)$. Moreover, forgone care was higher in patients with complications $(P=0.01)$, those with a history of hospitalization during the last year $(P=0.006)$ and those who rated their disease severity as very severe or very low compared to those who rated their disease severity as moderate $(P<0.001)$ Table 1.

The most frequently stated reason for forgoing care was financial burden resulting from the costs of disease treatment (41.5\%), followed by disappointment and dissatisfaction with treatment outcomes (9.3\%), lack of feeling the urge to medication and prescribed treatment (8.4), a long-distance from healthcare centers (8.0) and the long waiting time to receive services (6.4). Overall, $73.6 \%$ of patients reported these five items as the main reasons for forgoing care Table 2.

\section{Table 2 the most common reasons to forgone care}

\begin{tabular}{|c|c|c|c|}
\hline Number & Causes & Frequency & Percent \\
\hline 1 & The financial burden due to the cost of treatment & 222 & 41.5 \\
\hline 2 & Despair and dissatisfaction with the outcome of treatment & 50 & 9.3 \\
\hline 3 & Lack of feeling the urge to medication and prescribed treatment & 45 & 8.4 \\
\hline 4 & Long distances from the health care centers & 43 & 8.0 \\
\hline 5 & Long waiting time and a long process of treatment & 34 & 6.4 \\
\hline 6 & Dissatisfaction with the quality of provided care & 25 & 4.7 \\
\hline 7 & Unwillingness to take medication & 25 & 4.7 \\
\hline 8 & A lot of family and working activities & 22 & 4.1 \\
\hline 9 & Use of alternative therapies such as herbal medicines and traditional therapists & 16 & 3.0 \\
\hline 10 & Inadequate awareness and knowledge of the consequences of forgone treatment & 16 & 3.0 \\
\hline 11 & The lack of family support for following the treatment process & 14 & 2.6 \\
\hline 12 & $\begin{array}{l}\text { Lack of trust to skills and scientific competence of the medical practitioner or the provider of the } \\
\text { service }\end{array}$ & 12 & 2.2 \\
\hline 13 & poor physician-patient relationship & 7 & 1.3 \\
\hline 14 & $\begin{array}{l}\text { Inappropriate behavior of health care providers (discriminatory behavior, violence and } \\
\text { disrespectful behaviour) }\end{array}$ & 4 & .7 \\
\hline Total & & 535 & 100.0 \\
\hline
\end{tabular}

Table 3 Mean and SD of the reasons to forgone care (scores from 1 to 5) 


\begin{tabular}{|c|c|c|c|}
\hline Number & Questions & Mean & SD \\
\hline Q1 & - I do not have enough money to pay for the treatment of the disease & 3.12 & 1.583 \\
\hline Q2 & - I have a long distance from the health care centers & 2.04 & 1.268 \\
\hline Q3 & - The treatment process is too long and timely & 2.29 & 1.336 \\
\hline Q4 & - The waiting time for taking care is too long & 2.90 & 1.502 \\
\hline Q5 & - I am not satisfied with the quality of the provided care & 3.17 & 1.683 \\
\hline Q6 & - Health care provider deal with me violently and discriminately & 3.00 & 1.638 \\
\hline Q7 & - I do not need the prescribed treatment & 1.78 & 1.105 \\
\hline Q8 & - I have a lot of family and working activities & 1.79 & 1.162 \\
\hline Q9 & - I'm unwilling to take medication & 1.73 & 1.138 \\
\hline Q10 & - I would prefer to use alternative therapies such as herbal medicines and traditional therapists & 1.79 & 1.129 \\
\hline Q11 & - My doctor does not have a good relationship with me & 3.01 & 1.713 \\
\hline Q12 & - I cannot communicate properly with my doctor & 1.89 & 1.303 \\
\hline Q13 & - I do not have enough awareness and knowledge of the consequences of forgone care & 1.68 & 1.095 \\
\hline Q14 & - I do not have enough trust in skills, and scientific competence of the doctor & 3.06 & 1.718 \\
\hline Q15 & - I do not have enough trust in the service providers & 2.81 & 1.613 \\
\hline Q16 & - I do not have much desire to continue life & 1.53 & 1.017 \\
\hline Q17 & - My family does not support me in following and continuing the treatment process & 1.55 & 1.052 \\
\hline Q18 & - The behavior of health care providers is unfair and discriminatory & 2.79 & 1.578 \\
\hline
\end{tabular}

Of the four main factors which had an impact on forgone treatment, the highest mean score was related to the quality of care factor at $61.28 \pm 39.74$, followed by accessibility (37.01 \pm 25.12$)$, awareness and attitude towards disease $(18.52 \pm 18.87)$ and social support (17.22 \pm 18.80$)$.

The mean score of the quality of care factor was higher in men $(P=0.004)$, higher-income group $(P<.0001)$, Iranian health insurance coverage groups $(P=0.003)$, those who had a longer duration of disease $(P=.05)$, patients with complications $(P<0.001)$ and a history of hospitalization during the last year $(P=.006)$ and those who rated their disease severity as severe $(P<0.001)$.

The mean score of accessibility factor was higher in low-income groups $(P<.0001)$, patients with a lower level of education $(P<0.001)$, patients residing in rural areas $(P<0.001)$, those with Iranian health insurance coverage $(P<.0001)$, those without supplementary insurance coverage $(P<0.001)$, patients with the history of hospitalization during the last year and those who rated their disease severity as severe $(P<0.001)$.

The mean score of social support factor was higher in younger patients $(P=0.001)$, unmarried patients $(P=0.01)$, patients with higher levels of education $(P=0.04)$, those with a history of hospitalization during the last year, and those who rated their disease severity as severe $(P<0.001)$.

Finally, the mean score of awareness and attitude towards disease factor was higher in younger patients $(P=0.02)$, unmarried patients $(P=0.01)$, those with Iranian health insurance coverage $(P=0.006)$, patients with a shorter duration of disease $(P=0.003)$ and those whose current treatment was a lifestyle change compared to those who take oral agents or inject insulin $(P=0.009)$. Table 4.

Table 4 main factors affecting forgone care in terms of demographic, socioeconomic and disease-related variables 


\begin{tabular}{|c|c|c|c|c|c|c|c|c|c|}
\hline \multirow[t]{2}{*}{ Variables } & \multirow[t]{2}{*}{ Categories } & \multicolumn{2}{|l|}{ Social support } & \multicolumn{2}{|c|}{$\begin{array}{l}\text { Awareness and } \\
\text { attitude on disease } \\
\text { and treatment }\end{array}$} & \multicolumn{2}{|c|}{ Quality of care } & \multicolumn{2}{|l|}{ Accessibility } \\
\hline & & Mean \pm SD & $\begin{array}{l}\mathrm{P}- \\
\text { value }\end{array}$ & Mean \pm SD & $\begin{array}{l}\mathrm{P}- \\
\text { value }\end{array}$ & Mean \pm SD & $\begin{array}{l}\mathrm{P} \text { - } \\
\text { value }\end{array}$ & Mean \pm SD & $\begin{array}{l}\mathrm{P}- \\
\text { value }\end{array}$ \\
\hline \multirow[t]{2}{*}{ Gender } & Male & $18.11 \pm 19.13$ & \multirow[t]{2}{*}{.26} & $19.24 \pm 19.76$ & \multirow[t]{2}{*}{.37} & $66.04 \pm 39.34$ & \multirow[t]{2}{*}{.004} & $37.59 \pm 24.95$ & \multirow[t]{2}{*}{.57} \\
\hline & Female & $16.77 \pm 18.63$ & & $18.17 \pm 18.40$ & & $58.87 \pm 39.76$ & & $36.71 \pm 25.22$ & \\
\hline \multirow[t]{3}{*}{ Age } & $<40$ & $22.83 \pm 20.32$ & \multirow[t]{3}{*}{.001} & $21.89 \pm 19.87$ & \multirow[t]{3}{*}{.02} & $61.07 \pm 38.89$ & \multirow[t]{3}{*}{.98} & $41.14 \pm 25.01$ & \multirow[t]{3}{*}{.08} \\
\hline & $40-60$ & $17.33 \pm 19.73$ & & $19.07 \pm 19.30$ & & $61.12 \pm 39.55$ & & $37.31 \pm 25.03$ & \\
\hline & $>60$ & $15.63 \pm 17.02$ & & $17.05 \pm 18.00$ & & $61.52 \pm 40.25$ & & $35.59 \pm 25.17$ & \\
\hline \multirow[t]{2}{*}{ Marital status } & Married & $16.57 \pm 18.61$ & \multirow[t]{2}{*}{.01} & $17.88 \pm 18.66$ & \multirow[t]{2}{*}{.01} & $61.53 \pm 39.85$ & \multirow[t]{2}{*}{.65} & $36.45 \pm 25.23$ & \multirow[t]{2}{*}{.10} \\
\hline & Single & $20.19 \pm 19.43$ & & $21.45 \pm 19.59$ & & $60.18 \pm 39.36$ & & $39.52 \pm 24.52$ & \\
\hline \multirow[t]{2}{*}{ Income status } & $\begin{array}{l}<1500 \\
\text { international } \\
\$\end{array}$ & $18.29 \pm 21.01$ & \multirow[t]{2}{*}{.75} & $18.82 \pm 19.94$ & \multirow[t]{2}{*}{.49} & $53.21 \pm 38.56$ & \multirow[t]{2}{*}{$\begin{array}{l}< \\
.0001\end{array}$} & $42.51 \pm 25.96$ & \multirow[t]{2}{*}{$\begin{array}{l}< \\
.0001\end{array}$} \\
\hline & $\begin{array}{l}>1500 \\
\text { international } \\
\$\end{array}$ & $17.83 \pm 17.42$ & & $19.79 \pm 18.85$ & & $68.13 \pm 38.08$ & & $30.28 \pm 23.59$ & \\
\hline \multirow{4}{*}{$\begin{array}{l}\text { Education } \\
\text { status }\end{array}$} & Illiterate & $18.35 \pm 19.48$ & \multirow[t]{4}{*}{.04} & $17.83 \pm 17.95$ & \multirow[t]{4}{*}{.45} & $60.11 \pm 39.26$ & \multirow[t]{4}{*}{.32} & $40.97 \pm 25.00$ & $<$ \\
\hline & $\begin{array}{l}\text { Reading and } \\
\text { writing } \\
\text { ability }\end{array}$ & $15.82 \pm 17.89$ & & $18.41 \pm 19.64$ & & $60.22 \pm 40.44$ & & $37.19 \pm 24.95$ & \\
\hline & Diploma & $16.02 \pm 18.50$ & & $19.55 \pm 19.18$ & & $64.26 \pm 39.79$ & & $30.58 \pm 23.60$ & \\
\hline & $\begin{array}{l}\text { Academic } \\
\text { education }\end{array}$ & $21.48 \pm 19.50$ & & $21.28 \pm 19.59$ & & $67.80 \pm 38.57$ & & $26.30 \pm 25.03$ & \\
\hline Habitant & Urban & $16.83 \pm 18.70$ & .057 & $18.15 \pm 18.74$ & .07 & $61.39 \pm 40.26$ & .81 & $35.18 \pm 24.22$ & $<$ \\
\hline & Rural & $20.23 \pm 19.39$ & & $21.40 \pm 19.69$ & & $60.60 \pm 36.00$ & & $50.49 \pm 27.60$ & \\
\hline $\begin{array}{l}\text { Type of basic } \\
\text { health } \\
\text { insurance }\end{array}$ & $\begin{array}{l}\text { Iranian } \\
\text { health } \\
\text { insurance }\end{array}$ & $17.59 \pm 17.94$ & .53 & $20.65 \pm 18.83$ & .006 & $66.11 \pm 38.82$ & .003 & $41.40 \pm 25.96$ & $<.0001$ \\
\hline & $\begin{array}{l}\text { Social } \\
\text { security }\end{array}$ & $16.87 \pm 19.24$ & & $17.38 \pm 18.83$ & & $58.72 \pm 39.96$ & & $34.57 \pm 24.17$ & \\
\hline $\begin{array}{l}\text { Supplementary } \\
\text { health }\end{array}$ & Yes & $16.40 \pm 18.50$ & .23 & $18.48 \pm 18.23$ & .94 & $63.72 \pm 39.58$ & .09 & $30.74 \pm 23.14$ & $\begin{array}{l}<.0001 \\
.000\end{array}$ \\
\hline $\begin{array}{l}\text { insurance } \\
\text { status }\end{array}$ & No & $17.76 \pm 18.99$ & & $18.55 \pm 19.29$ & & $59.72 \pm 39.80$ & & $41.09 \pm 25.54$ & \\
\hline Chronicity (in & $<5$ year & $18.61 \pm 20.12$ & .12 & $21.01 \pm 20.96$ & .003 & $60.01 \pm 39.44$ & .05 & $37.51 \pm 24.52$ & .80 \\
\hline & $\begin{array}{l}5 \text { to } 10 \\
\text { years }\end{array}$ & $15.68 \pm 17.70$ & & $17.66 \pm 17.33$ & & $57.24 \pm 40.41$ & & $36.19 \pm 23.53$ & \\
\hline & $>10$ years & $16.88 \pm 18.11$ & & $16.74 \pm 17.45$ & & $64.47 \pm 39.43$ & & $36.98 \pm 26.60$ & \\
\hline Type of current & Oral pills & $16.46 \pm 18.85$ & .23 & $18.53 \pm 19.07$ & .009 & $59.26 \pm 40.68$ & .06 & $35.37 \pm 25.09$ & .55 \\
\hline & Insulin & $17.86 \pm 18.32$ & & $17.50 \pm 17.26$ & & $64.70 \pm 38.61$ & & $38.96 \pm 25.22$ & \\
\hline & $\begin{array}{l}\text { Change in } \\
\text { lifestyle } \\
\text { (change in } \\
\text { diet and } \\
\text { physical } \\
\text { activity) }\end{array}$ & $19.80 \pm 21.18$ & & $24.91 \pm 24.92$ & & $57.39 \pm 37.47$ & & $39.04 \pm 24.09$ & \\
\hline $\begin{array}{l}\text { Presence of } \\
\text { co-morbidity or }\end{array}$ & Yes & $17.38 \pm 18.65$ & .63 & $18.35 \pm 18.76$ & .57 & $64.50 \pm 39.58$ & $<.0001$ & $37.74 \pm 24.99$ & .08 \\
\hline
\end{tabular}

Page 7/15 


\begin{tabular}{|c|c|c|c|c|c|c|c|c|c|}
\hline complications & No & $16.74 \pm 19.30$ & & $19.09 \pm 19.25$ & & $51.00 \pm 38.57$ & & $34.66 \pm 25.46$ & \\
\hline \multirow{2}{*}{$\begin{array}{l}\text { Hospitalization } \\
\text { due to } \\
\text { complications } \\
\text { of DM in the } \\
\text { past year }\end{array}$} & Yes & $19.07 \pm 18.87$ & \multirow[t]{2}{*}{.03} & $18.36 \pm 17.43$ & \multirow[t]{2}{*}{.84} & $66.03 \pm 37.63$ & \multirow[t]{2}{*}{.006} & $40.86 \pm 25.50$ & \multirow[t]{2}{*}{.001} \\
\hline & No & $16.42 \pm 18.73$ & & $18.60 \pm 19.47$ & & $59.20 \pm 40.48$ & & $35.34 \pm 24.79$ & \\
\hline \multirow{3}{*}{$\begin{array}{l}\text { Disease } \\
\text { severity }\end{array}$} & Sever & $19.09 \pm 18.95$ & \multirow[t]{3}{*}{$<.0001$} & $19.57 \pm 18.51$ & \multirow[t]{3}{*}{.083} & $65.99 \pm 38.55$ & \multirow{3}{*}{.0001} & $41.29 \pm 24.64$ & \multirow{3}{*}{$\begin{array}{l}< \\
.0001\end{array}$} \\
\hline & Moderate & $14.79 \pm 17.85$ & & $16.89 \pm 17.91$ & & $46.17 \pm 37.28$ & & $32.82 \pm 24.10$ & \\
\hline & Low & $14.34 \pm 18.73$ & & $17.19 \pm 20.60$ & & $62.75 \pm 41.92$ & & $29.02 \pm 24.90$ & \\
\hline
\end{tabular}

Table 5 shows that factors of quality of care, accessibility, social support, awareness, and attitude on treatment and disease significantly affected foregone care in this population $(P<0.001)$. Accessibility and social support had the highest and lowest effect on forgone care, respectively.

Table 5 T-test results for main factors affecting forgone care

\begin{tabular}{|c|c|c|c|c|c|}
\hline Variable & Forgone care & Mean \pm SD & Mean Difference & $\mathrm{t}$ & P-value \\
\hline \multirow[t]{2}{*}{ Quality of care } & No & $57.78 \pm 39.79$ & \multirow[t]{2}{*}{-7.99} & \multirow[t]{2}{*}{-3.37} & \multirow[t]{2}{*}{.001} \\
\hline & Yes & $65.77 \pm 39.19$ & & & \\
\hline \multirow[t]{2}{*}{ Accessibility } & No & $31.53 \pm 25.25$ & \multirow[t]{2}{*}{-12.41} & \multirow[t]{2}{*}{-8.51} & \multirow[t]{2}{*}{$<.0001$} \\
\hline & Yes & $43.95 \pm 23.25$ & & & \\
\hline \multirow[t]{2}{*}{ Social Support } & No & $14.48 \pm 16.58$ & \multirow[t]{2}{*}{-6.15} & \multirow[t]{2}{*}{-5.53} & \multirow[t]{2}{*}{$<.0001$} \\
\hline & Yes & $20.64 \pm 20.75$ & & & \\
\hline \multirow[t]{2}{*}{ Awareness and attitude on disease and treatment } & No & $15.27 \pm 16.66$ & \multirow[t]{2}{*}{-7.21} & \multirow[t]{2}{*}{-6.52} & \multirow[t]{2}{*}{$<.0001$} \\
\hline & Yes & $22.49 \pm 20.53$ & & & \\
\hline
\end{tabular}

$* \mathrm{P}<0.01$ was considered as significant.

The results of the binary logistic regression model are shown in Table 6. The Dependent variable "forgone care" was dichotomized into 0 $=$ "no forgone care" and $1=$ "reported forgone care". The Hosmer-Lemeshow test results showed that the model is suitable $\left(\mathrm{x}^{2}=7.57, \mathrm{P}\right.$ value $=.47)$. The results indicate a significant association between forgone care and habitation status, disease severity, complications, quality, accessibility, as well as awareness and attitude. A 1 percent increase in the scores of awareness and attitude, accessibility and quality of care increases the odds of reporting forgone care by $2 \%, 1 \%$ and $1 \%$, respectively. Besides, the odds of reporting forgone care were $57 \%$ lower for patients with moderate disease severity than those with mild disease severity $(P=0.001)$. The odds of reporting forgone care were $49 \%$ greater for patients with complications than those without $(P=0.04)$.

Table 6 Binary Logistic Regression model for factors affecting forgone care 


\begin{tabular}{|c|c|c|}
\hline Variable & OR $(95 \% \mathrm{Cl})$ & p-value \\
\hline \multicolumn{3}{|l|}{ Age $($ Reference $=>60)$} \\
\hline$<40$ & $1.42(0.75-2.72)$ & 0.28 \\
\hline $40-60$ & $1.08(0.75-1.56)$ & 0.68 \\
\hline \multicolumn{3}{|c|}{ Marital status (Reference = Married) } \\
\hline Single & $1.22(0.80-1.86)$ & 0.36 \\
\hline \multicolumn{3}{|c|}{ Income (Reference = >1500 international \$) } \\
\hline$<1500$ international \$ & $0.84(0.57-1.23)$ & 0.37 \\
\hline \multicolumn{3}{|c|}{ Education status (Reference=Academic education) } \\
\hline Illiterate & $1.15(0.54-2.45)$ & 0.71 \\
\hline Reading and writing ability & $0.95(0.48-1.90)$ & 0.90 \\
\hline Diploma & $0.67(0.33-1.35)$ & 0.26 \\
\hline \multicolumn{3}{|c|}{ Type of basic health insurance (Reference=Iranian health insurance) } \\
\hline Social security & $1.12(0.78-1.60)$ & 0.53 \\
\hline \multicolumn{3}{|c|}{ Supplementary health insurance status (Reference $=$ No) } \\
\hline Yes & $0.87(0.61-1.25)$ & 0.47 \\
\hline \multicolumn{3}{|c|}{ Chronicity (in years) of DM (Reference $=>10$ years) } \\
\hline$<5$ years & $1.98(0.79-1.81)$ & 0.39 \\
\hline $5-10$ years & $1.001(0.65-1.54)$ & 0.99 \\
\hline \multicolumn{3}{|c|}{ Type of current treatment (Reference=Change in lifestyle) } \\
\hline Oral pills & $0.74(0.35-1.56)$ & 0.43 \\
\hline Insulin & $1.37(0.93-2.02)$ & 0.11 \\
\hline \multicolumn{3}{|c|}{ Complications (Reference=No) } \\
\hline Yes & $1.49(1.003-2.23)$ & 0.04 \\
\hline \multicolumn{3}{|c|}{ Hospitalization due to complications of DM in the past year (Reference $=$ No) } \\
\hline Yes & $1.23(0.82-1.83)$ & 0.31 \\
\hline \multicolumn{3}{|c|}{ Habitant status (Reference=Rural) } \\
\hline Urban & $2.21(1.25-3.94)$ & 0.007 \\
\hline \multicolumn{3}{|c|}{ Disease severity (Reference=Mild) } \\
\hline Sever & $1.08(0.71-1.64)$ & 0.71 \\
\hline Moderate & $0.43(0.26-0.72)$ & 0.001 \\
\hline Accessibility & $1.01(1.005-1.02)$ & 0.001 \\
\hline Awareness & $1.02(1.01-1.03)$ & 0.003 \\
\hline Quality & $1.01(1.001-1.02)$ & 0.04 \\
\hline Social & $1.001(1.008-1.02)$ & 0.48 \\
\hline
\end{tabular}

\section{Discussion}


Given the increasing growth of non-communicable diseases and the increased mortality due to these diseases in Iran, Iran's Package of Essential Noncommunicable (IraPEN) disease as a part of the Health Sector Evolution Plan, launched in 2014 by the Ministry of Health and Medical Education, to provide universal health coverage, including access to NCD prevention and care (24). (24). Given that IraPEN is developed based on the integrated and active care approach and evaluated through the control of parameters such as glucose, cholesterol and blood pressure, the evaluation of this program is essential in providing effective and continuous care to such patients at all care levels. Therefore, prevention of forgone care among diabetes patients can be considered as one of the evaluation indicators of this program. According to our results, nearly half of the patients reported forgone care, which was higher than in other studies. Röttger et al. conducted a study on patients with chronically ill in Germany. In their study, $14.1 \%$ of persons reported forgone care (25). In Towne SD Jr BJ et al. study, among those with diabetes, the rate of forgoing care due to cost was $17.9 \%$ in 2011 and $14.7 \%$ in 2015 , showing a slight decline (26). Given the implementation of Iran's Package of Essential Noncommunicable (IraPEN) disease, it can be concluded that the percentage of forgone care in diabetic patients is high, which is indicative of the poor performance of the health-care system.

In this study, type 2 diabetes patients reported the financial burden resulting from treatment costs as the leading cause of forgoing treatment. Since most patients were elderly individuals with low socioeconomic status, and only a small percentage of patients were covered by supplementary insurance, the disease's treatment cost was reported as the leading cause of forgone care. Bremer et al. in Germany showed that individuals with low income as well as people suffering from chronic illnesses face a higher financial burden and forgo health care services more frequently at the same time (27). Kim et al. conducted a survey in 28 countries in 2017 . They showed that income is significantly associated with forgone care in 21 of 28 examined countries, and people with lower income are more likely to forgo needed medical care (17). A study indicated that difficulty paying medical bills increased the effect of lack of health insurance in predicting forgone medical care and had a conditional effect on the association between education and forgone prescription drug care (28). Litwin et al. showed that forgone health care due to cost occurs among a substantial minority of older adults. Moreover, relinquished care is associated with younger old age, greater health needs and perceived economic inadequacy (29).

Frustration and dissatisfaction with the treatment outcomes reported as the second cause of forgone treatment. Given that diabetes and other chronic diseases require long-term care and consequences of their treatment are not immediate and short- term, in many cases, the patient cannot make a reasonable association between receiving treatment and its outcomes. Hence, low quality of care and poor assessment of treatment efficacy are important factors in forgone treatment.

The third and most important factor affecting forgone treatment was related to the urge to prescribe medication and treatment. Of course, it seems that this factor was of high importance in patients with shorter disease duration and lower illness severity. Patients' attitude towards disease plays an important role in patient adherence to prescribed medication. Whereby it is the duty of a physician and other providers to inform patients seriously about the consequences of irregular follow-up of treatment. The Fourth and fifth common cause of forgone treatment was related to a long distance from the health care centers and long waiting time to receive service. Long-distance from the health care centers was more likely to be common in patients residing in the rural area. Long waiting time as one of the dimensions of the quality of care was alone one of the most common causes of forgone treatment. $73.6 \%$ of the patients reported these five factors as the most important reason to forgo treatment. Therefore, focusing on managing these five factors can greatly reduce the rate of forgone treatment and play a crucial role in better management of diabetes. Röttger et al. conducted a study on patients with chronically ill and indicated that forgone care could be influenced by different factors, on the system as well as individual level, which in the individual level, negative experiences (i.e. perceived discrimination) with health care are significantly associated with forgone care (25).

The rate of forgone care was higher in patients without supplemental insurance. For people who were not covered by supplementary insurance, financial barriers to access had a greater impact on their treatment withdrawal. Supplemental insurance can improve financial access to required services by paying basic health insurance franchise and reimbursement of the cost of services that are not covered by basic health insurance. Galbraith et al. showed that Membership in a High-Deductible Health Plan (HDHPs) and lower-income were independently associated with a higher probability of delayed/forgone care due to cost (30). According to Reynolds et al., treatment discontinuation in diabetic patients was more in female, younger, Black or of Hispanic ethnicity, have more comorbidities, higher medication co-pays, start both OHAs together, have higher healthcare utilization before the index date and less likely to use prescription mail order in comparison with patients who did not discontinue (31). In another study, adherence was independently associated with older age, male sex, a higher level of education and income, use of mail-order versus retail pharmacies, higher daily total pill burden, and lower out-of-pocket costs, and also patients who were new to diabetes therapy were less likely to be adherent (32). Some other studies indicate an association between higher rates of forgone care and female sex, younger age, rural living, lack of health insurance, lack of financial support, low education levels, and poor health $(13,33-37)$. 
In our study, forgone care was more likely to be higher among patients with complications and a history of hospitalization due to DM during the last year and those who rated their disease severity as very severe or very mild. These three variables somehow assess the severity of the disease. Since more complex and expensive services are needed among those with higher disease severity, the cost of care and the quality and effectiveness of treatment is highly important in these patients. Besides this, providing qualified and affordable services to these patients can reduce the withdrawal rate from these patients' treatment.

Additionally, of the four main factors affecting forgone treatment, the quality of care had the highest impact on forgone treatment, followed by accessibility, awareness and attitudes towards disease and social support. This indicating the provided quality of care did not meet patients' expectations. Although the mean score of the accessibility factor was lower than the quality of care factor, most patients were of the opinion that the main reason to forgo treatment is related to financial burden resulting from the costs of disease treatment. Despite insurance coverage, diabetes imposes a considerable cost on diabetic patients, especially for lower-income patients. Therefore, in order to reduce the rate of withdrawal from treatment, it is necessary to provide financial support, such as strengthening insurance coverage and reducing copayment for low-income people to improve the financial access of these people to healthcare services. These results are in line with other studies in which forgone medical care was higher for those with lower incomes (16, 38, 39). In Towne SD Jr BJ et al. study, the rates of forgone medical care were higher among those with lower incomes $(<\$ 15,000 ; 24-31 \%)$ versus the highest (at/greater than $\$ 50,000$; less than 10\%), and higher for those with lower levels of education (without high school diploma/equivalent; above $20 \%$ ) versus all other higher education categories (ranging from 9-18\%) (26). In summary, the impact of factors related to the health-care system (health-care system based barriers) on forgone treatment was far more than factors related to the patient (patientbased barriers).

In this paper, the quality of the care factor's impact was higher among patients with high income and education levels. In comparison, the impact of accessibility factor was higher in patients with low income and education levels. In other words, forgone care in low- income and high-income groups was more likely to be related to difficult financial access and poor care quality. In summary, the quality of provided care could not meet the expectation of patients with higher socioeconomic status, and the cost of provided care was unaffordable for those with lower socioeconomic status.

Based on this survey, the impact of the accessibility factor was higher in patients residing in rural areas than those residing in urban areas. People living in rural areas face more financial and physical barriers to receiving specialized and advanced services. Therefore, in order to promote equity in access to health care, it is necessary to take appropriate supportive measures to reduce these barriers in rural people. In Towne SD Jr BJ et al. study, the residents of rural areas with a diagnosis of diabetes had higher rates of forgone medical care $(13-17 \%)$ than those in urban areas (11-15\%) (26).

Dissatisfaction with the quality of care, accessibility barriers, poor awareness and attitude towards disease and treatment were likely to have a greater impact on the forgone treatment of patients covered by Iranian health insurance than those covered by social security insurance. Although the HSEP and IraPEN have been implemented exclusively in the Ministry of Health and its covered institutions, and Iranian Health Insurance is also covered by the Ministry of Health, the performance of the Social Security Organization has been better in this regard, and Social Security Organization tends to provide more cost coverage and high-quality service for its patients covered.

Younger patients were more likely to report having forgone care due to poor social support and poor awareness and attitude towards the disease than older ones. This difference may be because the disease is less severe in young people, and the complications of the disease have not yet appeared, so both patients and their families pay less attention to the control and management of their disease. Also, people with shorter disease duration are more likely to have poor awareness and attitude towards the disease, which can have a greater impact on forgoing care. Therefore, in order to prevent worsening of the condition of young people and those who have shorter disease duration, it is necessary to provide more social support and the required training on the risk of incidence of disease complications to these patients. In Towne SD Jr BJ et al. study, forgone medical care was highest among those with lower age, with rates higher than $30 \%$ among those aged 18-24 for 2011 to 2013 (26).

The quality of care had a greater impact on forgoing care among patients with diabetes complications and a history of hospitalization because of diabetes complications, and those who rated their disease severity as very severe, as these people need more complex and advanced services and the quality of service is of importance regarding these services. Also, since these patients had lower social support, the probability of forgone care was higher among them. Also, access-related barriers have had a greater impact on forgone care in these patients, as disease status among these patients was more severe and required more complex and costly services. On the other hand, the financial burden caused by the treatment costs is considered as one of the most common causes of forgone care. 


\section{Conclusions}

The results showed that, despite the implementation of the Islamic Republic of Iran on a fast-track to beating non-communicable diseases (IraPEN), a considerable number of diabetics had a history of forgoing care, and the most important reasons for forgoing care were related to the financial barriers and dissatisfaction with the quality of care. Therefore, more financial support programs should be carried out, as well as the quality of provided care should be improved.

\section{Policy implication and recommendations}

In order to achieve the goals of the HSEP and IraPEN and to have the best performance in managing diabetes, healthcare providers should improve service quality for type 2 diabetes. Besides, health insurance organizations should improve financial coverage and access to healthcare among the vulnerable populations (people with lower incomes and education and those residing in rural areas). . also, health care providers should categorize diabetic patients based on age, sex, income and education level, urban and rural areas, as well as disease severity level in addition to general strategies, and exclusive political interventions to be designed for each group. Determining patients' copayment rate based on their income and ability to pay can be an effective strategy for reducing the forgone care in these patients. Also, focusing more on educational interventions in patients who are younger and have a shorter disease duration can be an effective strategy at the primary care level.

\section{Limitations}

Since the list of all patients was not available, and access to all patients was impossible, random sampling was not possible, so a sequential sampling method was used in this study.

\section{Declarations}

\section{Ethics approval and consent to participate}

This study was a part of a comprehensive PhD thesis work, ethically approved by the Ethics Committee of Tabriz University of Medical Sciences (Reference Number; IR.TBZMED.REC.1397.166). The participants were assured that any information they reveal would remain confidential and would be strictly used for research purposes only. Moreover, verbal informed consent was obtained from all patients, and participation in the study was voluntary. Informed consents from all participants have been obtained. All methods were performed in accordance with relevant guidelines and regulations that must be considered in research where humans are involved.

\section{Consent for publication}

Not applicable.

\section{Competing interests}

The authors declare that they have no competing interests.

Availability of data and materials

Data will be available upon reasonable request from the corresponding author.

\section{Funding}

This study was funded by Tabriz Health Services Management Research Center, Tabriz University of Medical Sciences (Grant Number; IR.TBZMED.REC.61521).

\section{Contributions}

H. J and R.KH. Z designed the manuscript. H.J analyzed and interpreted the data. H.M, S.F and S.H contributed to drafting the manuscript. H.J and S.H wrote the manuscript. H. J, R.KH. Z and N.H were involved in critical revision of the manuscript. All authors read and approved the final manuscript.

\section{Acknowledgements}


The authors gratefully acknowledge this research's financial support from the Research Deputy of Tabriz University of Medical Sciences. Our appreciation also goes to educational hospitals, diabetes clinics, primary healthcare centers affiliated to Tabriz University of Medical Sciences and private endocrinologist offices for collaborating with authors on data collection.

\section{References}

1. Association AD. Standards of medical care in diabetes. Introduction. Diabetes Care. 2016;39 (Supplement 1): S1-S2. .

2. Asche C, LaFleur J, Conner C. A review of diabetes treatment adherence and the association with clinical and economic outcomes. Clinical therapeutics. 2011;33(1):74-109.

3. Bogner HR, de Vries HF, O'Donnell AJ, Morales KH. Measuring concurrent oral hypoglycemic and antidepressant adherence and clinical outcomes. The American journal of managed care. 2013;19(3):e85.

4. Ho PM, Magid DJ, Masoudi FA, McClure DL, Rumsfeld JS. Adherence to cardioprotective medications and mortality among patients with diabetes and ischemic heart disease. BMC cardiovascular disorders. 2006;6(1):48.

5. Pladevall M, Williams LK, Potts LA, Divine G, Xi H, Lafata JE. Clinical outcomes and adherence to medications measured by claims data in patients with diabetes. Diabetes care. 2004;27(12):2800-5.

6. Hong JS, Kang HC. Relationship between oral antihyperglycemic medication adherence and hospitalization, mortality, and healthcare costs in adult ambulatory care patients with type 2 diabetes in South Korea. Medical care. 2011:378-84.

7. Juarez DT, Tan C, Davis J, Mau M. Factors affecting sustained medication adherence and its impact on healthcare utilization in patients with diabetes. Journal of Pharmaceutical Health Services Research. 2013;4(2):89-94.

8. Sokol MC, McGuigan KA, Verbrugge RR, Epstein RS. Impact of medication adherence on hospitalization risk and healthcare cost. Medical care. 2005:521-30.

9. Breitscheidel L, Stamenitis S, Dippel F-W, Schöffski O. Economic impact of compliance to treatment with antidiabetes medication in type 2 diabetes mellitus: a review paper. Journal of medical economics. 2010;13(1):8-15.

10. Hansen RA, Farley JF, Droege M, Maciejewski ML. A retrospective cohort study of economic outcomes and adherence to monotherapy with metformin, pioglitazone, or a sulfonylurea among patients with type 2 diabetes mellitus in the United States from 2003 to 2005. Clinical therapeutics. 2010;32(7):1308-19.

11. Organization WH. The world health report. Health systems financing: the path to universal coverage. Geneva. 2010.

12. Krůtilová V. Unmet Need For Health Care-A Serious Issue for European Elderly? Procedia-Social and Behavioral Sciences. 2016;220:217-25.

13. Röttger J, Blümel M, Köppen J, Busse R. Forgone care among chronically ill patients in Germany-Results from a cross-sectional survey with 15,565 individuals. Health Policy. 2016;120(2):170-8.

14. Levesque J-F, Pineault R, Hamel M, Roberge D, Kapetanakis C, Simard B, et al. Emerging organisational models of primary healthcare and unmet needs for care: insights from a population-based survey in Quebec province. BMC family practice. 2012;13(1):66.

15. McCusker J, Roberge D, Lévesque J-F, Ciampi A, Vadeboncoeur A, Larouche D, et al. Emergency department visits and primary care among adults with chronic conditions. Medical care. 2010:972-80.

16. Li X, Chen M, Wang Z, Si L. Forgone care among middle aged and elderly with chronic diseases in China: evidence from the China Health and Retirement Longitudinal Study Baseline Survey. BMJ open. 2018;8(3):e019901.

17. Kim TJ, Vonneilich N, Lüdecke D, von dem Knesebeck 0 . Income, financial barriers to health care and public health expenditure: a multilevel analysis of 28 countries. Social Science \& Medicine. 2017;176:158-65.

18. Chen J, Rizzo JA, Rodriguez HP. The health effects of cost-related treatment delays. American Journal of Medical Quality. 2011;26(4):261-71.

19. Soumerai SB, McLaughlin TJ, Ross-Degnan D, Casteris CS, Bollini P. Effects of limiting Medicaid drug-reimbursement benefits on the use of psychotropic agents and acute mental health services by patients with schizophrenia. New England Journal of Medicine. 1994;331(10):650-5.

20. Zgibor JC, Songer TJ. External barriers to diabetes care: addressing personal and health systems issues. Diabetes spectrum. 2001;14(1):23-8.

21. Mayer ML, Skinner AC, Slifkin RT. Unmet need for routine and specialty care: data from the National Survey of Children With Special Health Care Needs. Pediatrics. 2004;113(2):e109-e15. 
22. Esteghamati A EK, Koohpayehzadeh J, Abbasi M, Meysamie A, Noshad S, et al. Trends in the prevalence of diabetes and impaired fasting glucose in association with obesity in Iran: 2005-2011. Diabetes Research and Clinical Practice. 2014;103(2):319-27.

23. Comrey A, Lee H. A first course in factor analysis. Hillsdale, NJ, Lawrence Eribaum Associates. Inc, Publishers. 1992.

24. Hamzehkhani MS, Zahiri M, Haghighizadeh MH, Dehcheshmeh NF. Evaluating the quality of Iran's Package of Essential Noncommunicable (IraPEN) disease in the Eastern Health Center of Ahvaz: Viewpoints of the referring patients. Archives of Pharmacy Practice. 2020;1:62.

25. Röttger J, Köppen J, Blümel M, Busse R. The association between experienced discrimination and forgone care among chronically ill in GermanyJulia Röttger. European Journal of Public Health. 2015;25(suppl_3).

26. Towne SD Jr BJ, Ferdinand AO, Nicklett EJ, Smith ML, Ory MG. Assessing Diabetes and Factors Associated with Foregoing Medical Care among Persons with Diabetes: Disparities Facing American Indian/Alaska Native, Black, Hispanic, Low Income, and Southern Adults in the U.S. (2011-2015). International Journal of Environmental Research \& Public Health. 2017;14(5), 464.

27. Bremer P. Forgone care and financial burden due to out-of-pocket payments within the German health care system. Health economics review. 2014;4(1):36.

28. Baughman KR, Burke RC, Hewit MS, Sudano JJ, Meeker J, Hull SK. Associations between difficulty paying medical bills and forgone medical and prescription drug care. Population health management. 2015;18(5):358-66.

29. Litwin H, Sapir EV. Forgone health care due to cost among older adults in European countries and in Israel. European journal of ageing. 2009;6(3):167-76.

30. Galbraith AA, Soumerai SB, Ross-Degnan D, Rosenthal MB, Gay C, Lieu TA. Delayed and forgone care for families with chronic conditions in high-deductible health plans. Journal of general internal medicine. 2012;27(9):1105-11.

31. Reynolds K, An J, Wu J, Harrison TN, Wei R, Stuart B, et al. Treatment discontinuation of oral hypoglycemic agents and healthcare utilization among patients with diabetes. Journal of Diabetes and its Complications. 2016;30(8):1443-51.

32. Kirkman MS, Rowan-Martin MT, Levin R, Fonseca VA, Schmittdiel JA, Herman WH, et al. Determinants of adherence to diabetes medications: findings from a large pharmacy claims database. Diabetes care. 2015;38(4):604-9.

33. Zhou C, Ji C, Chu J, Medina A, Li C, Jiang S, et al. Non-use of health care service among empty-nest elderly in Shandong, China: a cross-sectional study. BMC health services research. 2015;15(1):294.

34. Åhs A, Burell G, Westerling R. Care or not care-that is the question: predictors of healthcare utilisation in relation to employment status. International journal of behavioral medicine. 2012;19(1):29-38.

35. Bodenmann P, Favrat B, Wolff H, Guessous I, Panese F, Herzig L, et al. Screening primary-care patients forgoing health care for economic reasons. PloS one. 2014;9(4):e94006.

36. Bryant T, Leaver C, Dunn J. Unmet healthcare need, gender, and health inequalities in Canada. Health policy. 2009;91(1):24-32.

37. Ronksley PE, Sanmartin C, Quan H, Ravani P, Tonelli M, Manns B, et al. Association between chronic conditions and perceived unmet health care needs. Open Medicine. 2012;6(2):e48.

38. Towne S, Bolin J, Ferdinand A, Nicklett E, Smith M, Ory M. Assessing diabetes and factors associated with foregoing medical care among persons with diabetes: Disparities facing American Indian/Alaska native, black, hispanic, low income, and southern adults in the US (2011-2015). International journal of environmental research and public health. 2017;14(5):464.

39. Mielck A, Kiess R, von dem Knesebeck O, Stirbu I, Kunst AE. Association between forgone care and household income among the elderly in five Western European countries-analyses based on survey data from the SHARE-study. BMC health services research. 2009;9(1):52.

\section{Figures}




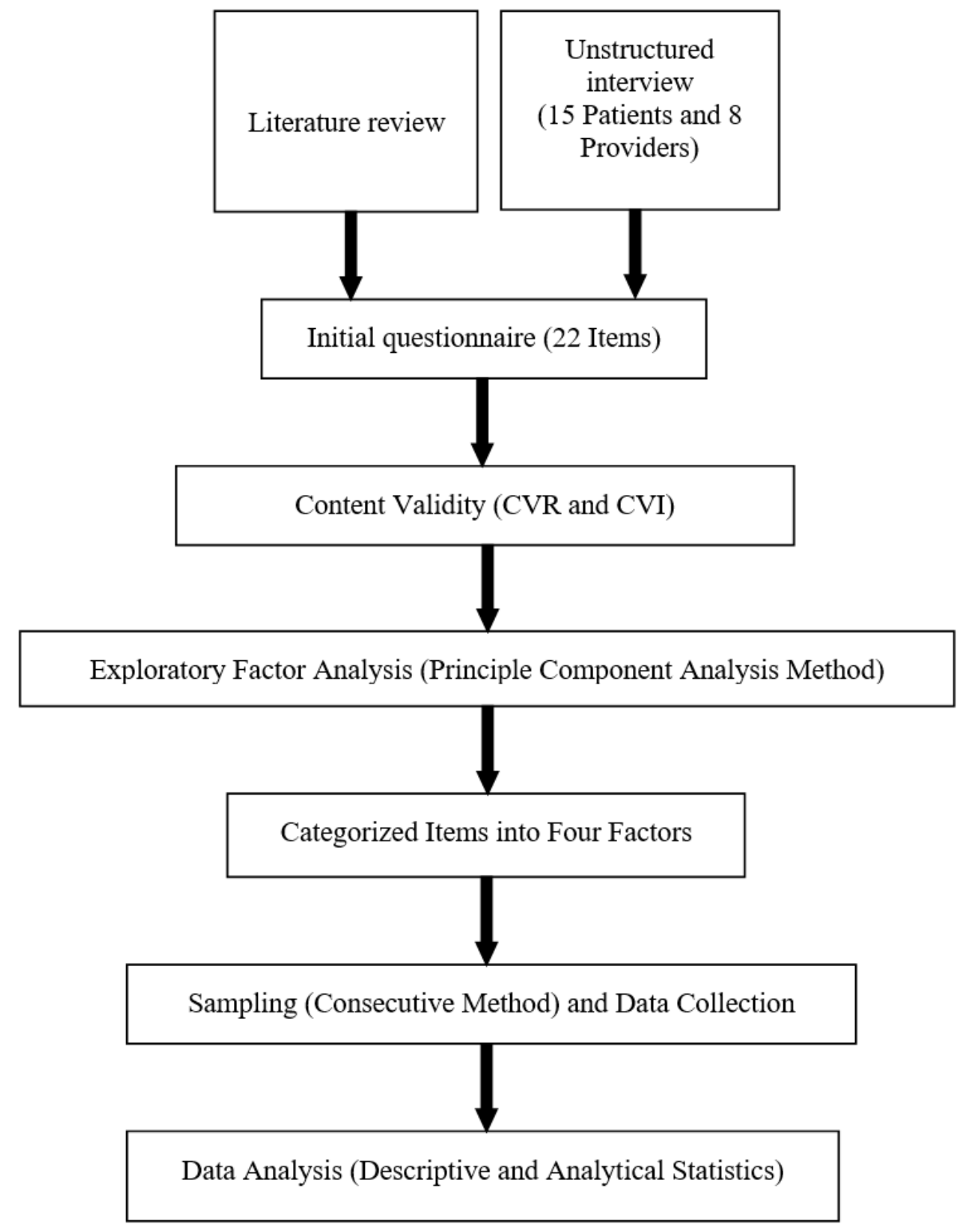

Figure 1

Methodological flowchart

\section{Supplementary Files}

This is a list of supplementary files associated with this preprint. Click to download.

- Appendix.doc 